\title{
Teaching e-Commerce Personalization Technology: The Need for a Comprehensive View
}

\author{
Miguel-Angel Sicilia \\ University of Alcalá, Alcalá de Henares (Madrid), Spain \\ msicilia@uah.es \\ Executive Summary
}

Personalization technology has become an important topic in e-commerce, fostered by the emergence of the relationship-marketing paradigm. But teaching e-commerce personalization technology is a challenging task, since it requires a balance between marketing and management and technical implementation issues that must be calibrated according to the student's background, all of this without losing a holistic perspective of the subject. In this paper, we describe the result of our experiences in teaching personalization, sketching both a conceptual framework and a set of curricular objectives that provide a balanced and comprehensive view of the field in its current state.

The conceptual framework for the topic area puts in relationship technical and business issues as part of marketing in e-business strategy. The main categories are the topics related to "partner interaction", including adaptive hypermedia and filtering of information, and "relationship maintenance", including user profiling and modeling along with common market segmentation techniques as related to the paradigm of relationship marketing. Concepts of human-computer interaction are required to aid in understanding the assessment techniques of personalization techniques, and privacy and legal issues should also be considered. The concept of CRM (Customer Relationship Management) systems crosscuts interaction and relationship maintenance issues, and could be used as a criteria for curriculum organization in some cases. Seven general curricular goals are identified as key aspects of the curriculum in personalization technology, including foundations of relationship marketing, user profiling and modeling, hypermedia and adaptive hypermedia concepts, the use of personalization as a tool in marketing strategy, CRM, privacy and legal issues and mass customization. The four first aspects are considered as the core of the curriculum, and they should be addressed to some extent depending on the background and interest of the students.

The content of each particular course can then be tuned to diverse student profiles by putting more emphasis in some of the goals, without losing the global view of personalization as a component of a global e-marketing strategy. Rule-base personalization systems represent an appropri-

Material published as part of this journal, either on-line or in print, is copyrighted by the publisher of the Journal of Information Technology Education. Permission to make digital or paper copy of part or all of these works for personal or classroom use is granted without fee provided that the copies are not made or distributed for profit or commercial advantage AND that copies 1) bear this notice in full and 2) give the full citation on the first page. It is permissible to abstract these works so long as credit is given. To copy in all other cases or to republish or to post on a server or to redistribute to lists requires specific permission and payment of a fee. Contact Editor@JITE.org to request redistribution permission. ate case for introducing the technical content of personalization, and marketing oriented content should be approached from a clear concept of relationship value, as the key concept from which marketing tactics and techniques are derived.

Keywords: Personalization, relationship marketing, e-commerce education. 


\section{Introduction}

Personalization in the context of e-commerce encompasses all the activities, business rules and technological support required to build and maintain a personalized relationship with a customer or business partner or, in some cases, with a group of similar customers or partners. Such a potentially complex system of elements results in some form of tailoring of the interaction between the organization and the user. This is nowadays in most cases realized through Web pages that select the information items that are supposed to be more relevant to the user. Book recommendations in on-line shops like Amazon are a typical example, but personalized interaction also encompasses personalized commercial e-mail delivery, targeted promotions and even the dynamic restructuring of the link structure of the Web site, in an attempt to ease navigation for a particular individual. Personalization is therefore an important piece in the process of conducting e-commerce, and also in the overall electronic business strategy, since it may include interactions other than selling such as customer support or community services.

Personalization has become in the last few years an important issue in e-commerce as an advanced relationship management strategy. As such, technology must be put in a context of relationship marketing (Sheth \& Parvatiyar, 2000) to clarify the goals and the theory behind concrete personalized interaction tactics.

As the number of advanced e-commerce programs offered by universities grow (Smith \& Stobartg, 2002), the need for a conceptualization of personalization technology in the context of ebusiness becomes more and more important. It should be noted that since personalization is a cross-cutting concern for many interaction related e-commerce activities (just as security and privacy are), the topic can be approached from several different and complementary perspectives. In addition, the relationship marketing approach makes personalization a central characteristic of ecommerce endeavors. This is the case either if it is carried out by conventional means-i.e. controlled directly by marketing staff - or if it is partially or completely automated through software by means of business rules (or any other kind of technological support). In the case of organizations supporting hundreds or thousands of customers, automation becomes an unavoidable requirement to achieve a feasible and cost effective relationship management strategy. Consequently, personalization can be considered an important element when teaching e-commerce. From a holistic perspective, the aim of achieving a sound understanding of the topic requires a balanced view, encompassing both marketing and managerial issues, and also an outlook of the state of the art in personalization technologies.

Surprisingly, personalization is not considered nowadays a fundamental topic in most existing postgraduate e-commerce programs, or at least it is not considered as a topic in its own right in most existing syllabuses. This may be due to the lack of comprehensive resources on the topic in the form of books, or perhaps because being an expert in the field requires a wide array of skills

from different disciplines to be mastered. These skills include marketing, Web engineering, artificial intelligence (AI) and human-computer interaction (HCI). On the one hand, marketing and Web engineering provide the theoretical and practical, managerial and technical ground for the discipline. On the other hand, understanding of $\mathrm{AI}$ and $\mathrm{HCI}$ is required to be able to assess tools and approaches, and also to design and evaluate the technical solution. This is due to the fact that human factors - and, especially usability - are important in the design and assessment of the resulting tailored interactions, and existing personalization solutions are AI-based systems with particular implementation paradigms (Fink \& Kobsa, 2000).

This paper describes the goals and curricular structure of a "Personalization in e-commerce" module, intended to give students a multi-disciplinary and holistic view of the topic. It is based on previous experiences in a module taught since 2002 in a Postgraduate degree in Electronic Commerce offered by the University of Salamanca (Spain). The students of this degree were all BSc 
holders with a diversity of backgrounds, though a majority of them came from Computer Science studies. Parts of the content and structure of the module were also taught as part of a doctorate course on hypermedia applications at the University of Alcalá (Spain), in this case focusing more on the research issues related to adaptive hypermedia and collaborative filtering algorithms. Further, some technical and business content was previously used in corporate training seminars of about three hours about the topic, inside Spanish e-commerce development firms, and targeted both to developers and managers. The second edition of the postgraduate program benefited from the feedback from the first one. Therefore, the sequence of presentation of the content was rearranged to ease the understanding of the applicability and assessment of concrete personalization techniques. The goals and content described in this paper are presented as a comprehensive framework for teaching the topic. That overall framework can subsequently be tailored to diverse audiences by putting more emphasis in certain parts of the content than others. However this should be done without neglecting to cover the subset of core concepts about personalization technology that should be introduced regardless of the background of the students.

In the rest of this paper, a conceptual framework of personalization technology is provided, along with the overall goals and competences that would be desirable to acquire through a postgraduate personalization module. Then, the principal trade-off issues of the material to be taught are discussed, and the resulting curricular structure is described. Finally, some concluding reflections about the topic are provided.

\section{Overall Curricular Goals}

As a matter of fact, students of e-commerce courses - and especially postgraduate ones - come from a variety of disciplines, including business and economics, engineering, international affairs and even experimental psychology. This diversity requires that the level of difficulty of the topics must be carefully selected to be understood by all the students while still challenging more advanced students. This is recognized in existing reported experiences (e.g. Dhamija, Heller, \& Hoffman, 1999). Consequently, it is important to provide interdisciplinary motivation to students of all backgrounds. Furthermore, the integration of the topics in the program should be carefully introduced.

The first section of this paper shows the coverage that personalization is given in some existing ecommerce programs. Next, we discuss our approach for teaching the topic, in light of our recent experiences. Finally, the overall conceptual framework is described, along with the concrete goals it pursues.

\section{A Look at Some Existing Programs}

A number of seminars and programs around the world now offer courses, tracks or modules somewhat dealing with personalization. From among them, some are directly related to the ecommerce context while others focus on other applications of Web personalization techniques. In what follows we mention some significant examples. We have not included an exhaustive catalog since the offerings with syllabuses available through the Web are few, and with a level of detail in their description that do not help in comparing topic coverage.

For example, the Department of Information and Computer Science of the University of Hawaii has offered a course on "Personalization in Information Delivery" (Quiroga, 2003), which focuses on information filtering, but its objectives and content are far from those required for ecommerce-oriented education. Although some material in this course-essentially user modeling techniques - would be also required in an e-commerce program and filtering techniques can be applied to build personalized interactions, it does not provide an outlook of the overall business framework. 
In many other e-commerce programs, personalization is not an independent topic and is only treated as a part of another element in the syllabus of the program or a course inside the program. For example, the syllabus of the "Master of Science in E-commerce" offered at the Carnegie Mellon Institute for e-commerce (Carnegie Mellon, 2003), only mentions personalization as one of the ten topics of the "eCommerce Technology" course.

In addition, personalization in e-commerce as an independent course is in some cases organized around technological issues, relegating the overall marketing and business context to a secondary status. This was the primary approach in our first $\mathrm{PhD}$ course, since all the students had a computer science background. Another example of this kind is the course CSE715 "Personalization and Customization in E-Commerce" offered at the Computer Science and Engineering Department of the University of Buffalo (Computer Science and Engineering Department, 2003). The structure of this course presents progressively a number of important technical topics: user profiling, filtering techniques, Web usage analysis, intelligent agents, localization, preference modeling, applications and privacy. Although this kind of course structure is appropriate to acquire the knowledge and abilities to implement technical personalization solutions, it lacks a global view providing the competencies required contextualizing and critically assessing the design of personalization technologies oriented towards concrete business goals. This also occurs often in corporate training courses that are restricted to personalization technologies and/or off-the-shelf personalization packages. Many times the most difficult competences to be acquired are related to being capable of moving from marketing requirements to effective implementation, and technical contents provide only a subset of the skills required, neglecting the higher level managerial issues that actually motivate the implementation of personalization.

\section{Conceptual Framework}

Our conceptual framework regarding personalization technology in e-commerce is depicted in Figure 1. The figure depicts the main topics that we have addressed and their relationships. Squares are used to depict marketing-oriented elements specific of the relationship approach (Tinsley, 2002), and ovals are used to represent more technically oriented implementation topics. We have adopted a differentiation between topics that are mostly related to the modeling and representation of relationships (labeled "relationship maintenance" in Figure 1). Those that are related to interaction with partners (customers or other organizations) are labeled "Partner interaction". This division roughly corresponds to the two main issues in the field of adaptive (personalized) hypermedia i.e. user modeling and adaptation (Brusilovsky, 2001). In many cases, the term user profiling is used to refer to the collection of raw data (the "clickstream") from Web visitors, while the term user modeling is used to refer to the elaboration of such data into meaningful information.

The point of departure of any comprehensive account of personalization technology in ecommerce should be that of considering it as a piece inside a global e-business strategy, and especially, of a marketing strategy that considers the Internet as a key piece that provides improved efficiency and effectiveness to the firm (Chang, Jackson \& Grover, 2003). Concretely, it can be framed as a kind of differentiation strategy focused on loyalty in terms of Porter's (1980) model. Here the term "marketing strategy" is used in a broad sense, encompassing both customeroriented interactions and also business networking and business to business (B2B) marketing. According to the definitions provided by Osterwalder \& Pigneur (2002), business strategies are based on the description of actors, roles, exchanges and dynamics inside a particular business model that determines the operational-level actions that are most appropriate to implement the strategy. Hence, the purpose of each concrete personalization technology should be put in the context of a given business model (or family of similar business models), and its motivation should be traced to concrete business model entities and roles. According to this view, e- 


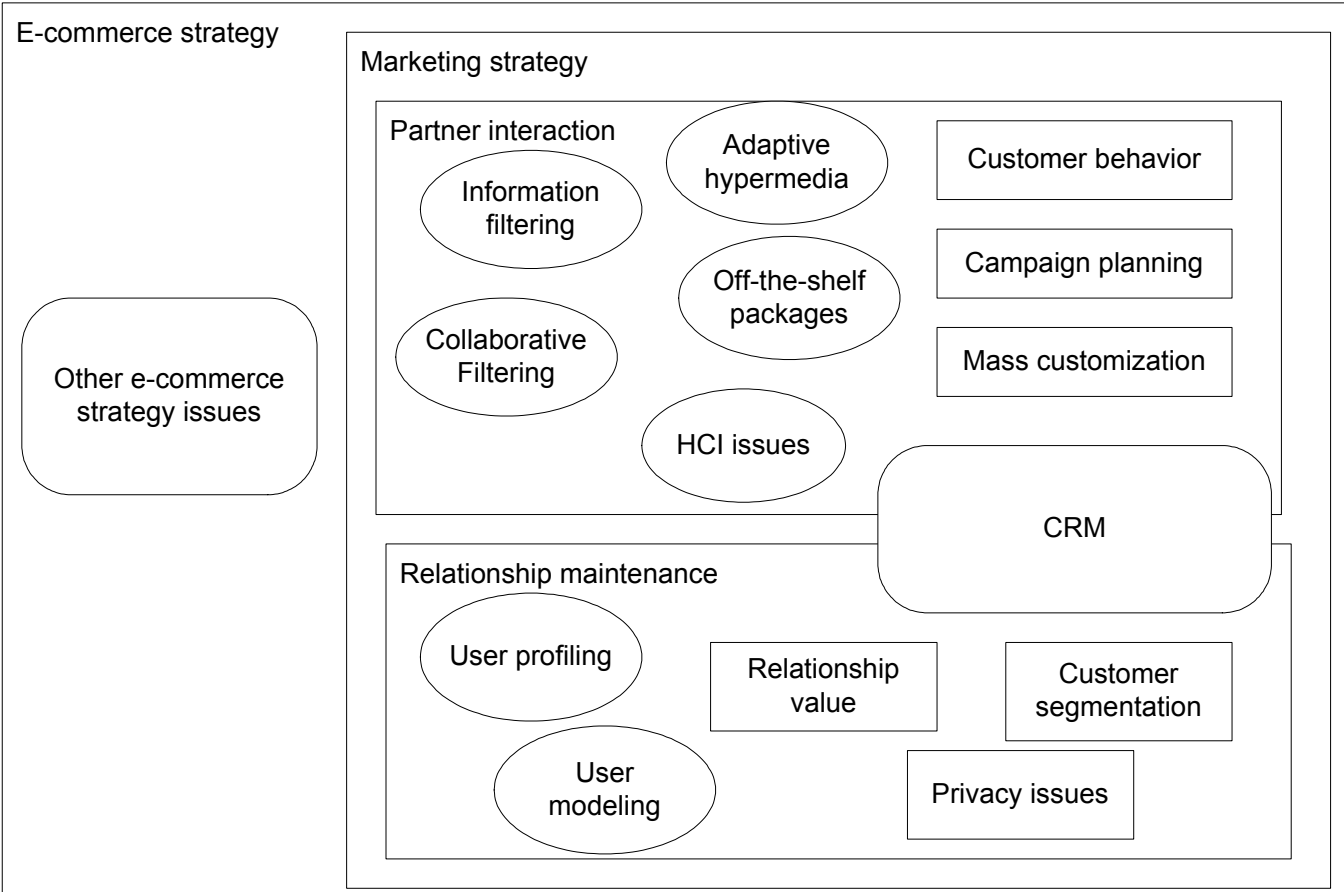

Figure 1. E-commerce Personalization Technology Conceptual Framework

marketing strategies and revenue models are the foundational elements required to accommodate the rest of the knowledge regarding e-commerce personalization, according to a constructivist perspective (Fosnot, 1996). Of course, other elements of e-business models are connected in some way to personalization issues, for example, flexible manufacturing and procurement systems supported by electronic means are crucial in mass customization endeavors (Piller, Reichwald \& Möslein, 2000), but they should not be considered as mandatory but optional in e-commerce personalization courses.

Relationship maintenance topics must be structured around a notion of relationship value. Although some models and methods currently exist to clarify such a concept (Hogan, 2001), the topic is by no means closed, and teachers should regularly update its content. Relationships as company assets should be motivated as a "paradigm change" from previous shortcomings of the measure of customer value through profitability analysis (Ryals, 2002), along with an emphasis on customer retention and loyalty (Peppers \& Rogers, 1997) that was not commonplace in previous mass market approaches. Of course, controversies exist about the novelty of the relationship approach, e.g. (Petrof, 1998), but the conceptual apparatus is definitely richer than previous ones with respect to the variables considered in measuring customer value. Then, the essentials of customer (or market) segmentation techniques can be introduced in light of the relationship approach. Classical segmentation (Wedel \& Kamakura, 1999) can be augmented with segmentation criteria directly related to relationship value, as generalizations that cope with variables subject to some degree of uncertainty, like estimated customer lifetime and "grow-ability" of the relationship (Sicilia \& García, 2003). Security and privacy issues should at least be raised in this context, since building a rich database of relationship information requires the willingness of customers to provide their data, and privacy is a determinant of the success of relationship marketing, as recognized by studies of the Personalization Consortium (Personalization Consortium, 2003).

All the previously-described marketing-oriented issues can be subsequently introduced as the technical means to build, refine and maintain relationship databases. User profiling can be con- 
sidered as the gathering of raw data relevant to each relationship, and user modeling can be considered to encompass all the analysis and refinement procedures on that raw data. These two technical topics can be treated in diverse ways, with different level of technical detail. A simple exposition adequate for both technical and non-technical backgrounds may describe user models as a simple set of relational tables with attributes describing users and groups. In fact, several rule-based personalization commercial packages provide this kind of straightforward user model storage format. For more technical or research orientations, knowledge representation (Davis, Shrobe \& Szolovits, 1993) and automated reasoning techniques can be introduced from an AI viewpoint. Formal ontologies and data mining are two prominent AI-related techniques that deserve particular attention. Formal ontologies are an interesting emerging topic (Fensel, 2001) that enable the construction of "intelligent" functionality based on shared domain conceptualizations (e.g. a common conceptualization of products and services). Data mining techniques provide sophisticated tools to elaborate the user model of customer and partners, but their usage criteria must be founded on marketing concepts (Rygielski, Wang \& Yen, 2002). As such, the technical issues of data mining could be introduced as a discovery technique in market analysis and customer segmentation.

The "Partner Interaction" part in Figure 1 encompasses the issues related to the exploitation of the information in the relationship model to provide a personalized experience and treatment of each user. From the marketing viewpoint, a review of the most important results in customer behavior studies can be used to better inform the psychological aspects of the interaction, and common campaign planning and tracking can be introduced as essential material. The topic of mass customization can be presented as a branch of e-commerce personalization regarding flexible personalized configuration of goods supported by flexible production chains (Piller, 2002).

From the technical viewpoint, two approaches (or a mixture of them) can be taken to teach the technological background of personalized interactions. On the one hand, a focus on commercial systems can be selected ensuring that the two most relevant techniques: rule-based personalization and collaborative filtering are introduced. A review of some of the commercial "off-theshelf packages" can be found in (Fink \& Kobsa, 2000), Popular rule-based commercial systems include BEA WebLogic (BEA WebLogig, 2003) and ATG Dynamo (ATG Dynamo, 2003) personalization suites, and perhaps the most popular product including collaborative filtering is that of Net.Perceptions (NetPerceptions, 2003). On the other hand, a more research-oriented focus may include details of collaborative filtering research, rule-based adaptive hypermedia systems (Brusilovsky, 2001), and information filtering as a more general framework for collaborative filtering.

Personalization paradigms should be introduced as concrete technical means to implement marketing decisions. There are three issues of special relevance that can be considered as essential concepts:

- General adaptive hypermedia issues. Adaptive hypermedia is a new and active area of research concerned with personalization in hypermedia systems (including Web personalization). The survey reported by Brusilovsky (2001) can be used to provide an overview of the diverse types of personalization technologies that have been investigated to date, like adaptive presentation and adaptive linking. These concepts help students think in terms of abstract hypermedia components: nodes, contents, anchors and links, beyond concrete limitations and implementation issues of common Web languages like HTML.

- Collaborative filtering technologies applied to e-commerce (Sarwar, Karypis, Konstan, \& Riedl, 2000). Recommender systems and procedures that use them must be motivated in the context of customer behavior as described in (Kim, Cho, Kim, Kim, \& Suh, 2002). In 
addition to cross- and up-selling behaviors, similar approaches to preference modeling are use to customize electronic catalogs (Yen \& Kong, 2002).

- Rule-based personalization. Rules are an easy to understand approach to personalization, found in several research and commercial systems. Declarative rules provide an straightforward way to express marketing rules, so that it can be introduced earlier to provide a first glimpse on how personalization can be implemented.

Finally, some basic background on usability and related HCI issues should be introduced due to the fact that increased usability is often considered an evaluation criterion for the introduction of personalization techniques in Web systems (Benyon, 1993), especially in the case of mobile systems with limited screen size and interaction capabilities (Smyth \& Cotter, 2002), in which making navigation paths shorter becomes critical in e-commerce scenarios.

The topic of Customer Relationship Management (CRM) systems crosscuts interaction and maintenance issues, since a CRM system can be considered a systemic view of a relationship marketing strategy encompassing both the technological and the managerial structure (Dyché, 2001). CRM could be used as a guiding principle for the organization of the curriculum, as approached in the specialized MBA program offered at the Hankamer School of Business (Baylor University, 2003), but for more high management-oriented audiences.

It should be noted that the topics depicted in Figure 1 allow for a variety of sequencing of the topics described. Nonetheless, some order is required due to the fact that some topics are prerequisites for others. For example, some notions of marketing strategy such as the framework to understand personalization in e-commerce are required at the beginning, and just after that, it is advisable that students are exposed to some examples of personalized interaction to get an initial idea of the final results. Real-world examples can be used to illustrate the process of recommending or filtering information. In addition, user modeling is better understood after illustrating the raw profiles of connections that Web servers store, and customer segmentation should come after explaining the notion of relationship value.

As a final note, although personalization is often referred to as a business to client (B2C) functionality, many of its activities can be also applied to B2B relationships. It should be noted that B2B-oriented relationship marketing is gaining more attention (Hogan, 2001) and that view should not be neglected. An important body of research in that direction can be found in the work of the Industrial Marketing and Purchasing Group (IMP, 2003).

\section{Curricular Goals}

In accordance with the above-described conceptual framework, the overall goal of an ecommerce personalization course is that of providing an understanding of current personalization technologies as tools to implement relationship-marketing decisions. As such, a number of learning goals can be established, along with concrete topics and basic abilities intended to be acquired by students. These overall goals are listed in Table 1, along with some example content, resource and practices that we have used in our previous experiences. The elements of the conceptual framework depicted in Figure 1 can be recognized in the topics of Table 1, but organized around coherent modules with a single, high-level objective.

Providing an in-depth coverage of the wide range of topics provided in Table 1 would require more time than is often available in postgraduate program modules. Consequently, teachers have to carefully select the content and activities that provide at least a basic account of the topics, without overwhelming students with excessive details, and adjusting the syllabus to the available schedule. It should be noted that the curricular goals of our program in e-commerce personalization are the same for the possible variants of its presentation described above, so that only the 
degree of depth with which specific goals are addressed must be tailored to the background of the audience.

Table 1. Overall curricular goals for a course on e-commerce personalization

\begin{tabular}{|c|c|c|c|}
\hline$\#$ & Topic & Objectives & Example Content and Practice \\
\hline 1 & $\begin{array}{l}\text { Foundations of the } \\
\text { relationship marketing } \\
\text { approach. }\end{array}$ & $\begin{array}{l}\text { Understand the relationship approach in } \\
\text { contrast to other marketing paradigms. } \\
\text { Understand the major concepts of the } \\
\text { relationship approach. } \\
\text { Contextualize personalization as a tool to } \\
\text { implement purposeful marketing tactics. } \\
\text { Understand the main factors involved in } \\
\text { current approaches to relationship value. }\end{array}$ & $\begin{array}{l}\text { Brief historical accounts of marketing. } \\
\text { Basic material about campaign planning and management, } \\
\text { e.g. (Bayne, 2000) and customer behavior, e.g. (Sheth, } \\
\text { Mittal \& Newman, 1998). } \\
\text { Excerpts from Pepper and Roger's books, e.g. (Peppers \& } \\
\text { Rogers, 1997). } \\
\text { Examples of relationship approaches to marketing, some } \\
\text { reports can be found in (Sheth, \& Parvatiyar, 2000) }\end{array}$ \\
\hline 2 & $\begin{array}{l}\text { User (cus- } \\
\text { tomer/partner) profil- } \\
\text { ing and modeling } \\
\text { issues. }\end{array}$ & $\begin{array}{l}\text { Understand database and knowledge- } \\
\text { based representations for user models. } \\
\text { Understand the possibilities and limita- } \\
\text { tions of Web session tracking. } \\
\text { Understand the role of data mining and } \\
\text { other data analysis techniques as user } \\
\text { modeling techniques. } \\
\text { Integrate the knowledge on customer } \\
\text { segmentation as a user modeling task. }\end{array}$ & $\begin{array}{l}\text { Example designs of customer databases, e.g. the database } \\
\text { structure of a personalization package. } \\
\text { The basics of Web session management and tracking (in- } \\
\text { cluding cookies) can be covered to provide an account of } \\
\text { the technical base for recording the clickstream. } \\
\text { A technical survey of the diverse variants of Web mining is } \\
\text { provided by Kosala \& Blockeel (2000). } \\
\text { Practice with a customer segmentation tool. The book of } \\
\text { Lilien, and Rangaswamy (2002) provides resources for that } \\
\text { purpose. }\end{array}$ \\
\hline 3 & $\begin{array}{l}\text { Hypermedia and adap- } \\
\text { tive hypermedia un- } \\
\text { derstanding }\end{array}$ & $\begin{array}{l}\text { Identify the abstract elements of hyper- } \\
\text { media systems. } \\
\text { Identify and categorize adaptive hyperme- } \\
\text { dia behaviors (text adaptation, link adapta- } \\
\text { tion, direct guidance, etc.) }\end{array}$ & $\begin{array}{l}\text { Brusilovsky's surveys on adaptive hypermedia technologies } \\
\text { (Brusilovsky, 2001) provide pointers to a large number of } \\
\text { example research systems. } \\
\text { Here the topic of usability and related HCI concepts can be } \\
\text { used as a motivation for personalization connected or not } \\
\text { with revenue models. } \\
\text { Information filtering topics (a kind of adaptive behavior) } \\
\text { can be expanded if appropriate for the audience. }\end{array}$ \\
\hline 4 & $\begin{array}{l}\text { Implementation of } \\
\text { marketing strategies } \\
\text { through personaliza- } \\
\text { tion }\end{array}$ & $\begin{array}{l}\text { Understand the philosophy of current } \\
\text { recommender systems (collaborative } \\
\text { filtering). } \\
\text { Design cross-selling and up-selling situa- } \\
\text { tions with the help of user models. }\end{array}$ & $\begin{array}{l}\text { The underlying ideas of collaborative filtering can be illus- } \\
\text { trated by describing the statistical model of preferences } \\
\text { published in earlier works of the GroupLens research group, } \\
\text { e.g. (Resnick, Iacovou, Sushak, Bergstrom, \& Riedl, } \\
\text { 1994). } \\
\text { Off-the-self packages can be used for illustration purposes. }\end{array}$ \\
\hline 5 & $\begin{array}{l}\text { CRM system under- } \\
\text { standing }\end{array}$ & $\begin{array}{l}\text { Conceptualize a CRM system as an in- } \\
\text { formation system that spans across ana- } \\
\text { lytic and decision marketing activities } \\
\text { regarding marketing. }\end{array}$ & $\begin{array}{l}\text { Presentation of the foundations of CRM from a holistic } \\
\text { viewpoint, as in (Dyché, 2001). } \\
\text { Illustration of CRM functionalities through a commercial } \\
\text { package. }\end{array}$ \\
\hline 6 & $\begin{array}{l}\text { Privacy and legal } \\
\text { issues }\end{array}$ & $\begin{array}{l}\text { Understand the role of privacy and trust as } \\
\text { a key determinant of the applicability of } \\
\text { personalized interactions. } \\
\text { If convenient, present national and/or } \\
\text { international legislative details. }\end{array}$ & $\begin{array}{l}\text { The Personalization Consortium provides basic material and } \\
\text { reports of studies concerning the topic. }\end{array}$ \\
\hline 7 & Mass customization & $\begin{array}{l}\text { Understand mass customization as a flexi- } \\
\text { ble marketing approach with configurable } \\
\text { products and services, where information } \\
\text { technology and personalization take a } \\
\text { prominent role. }\end{array}$ & $\begin{array}{l}\text { Frank Piller provides a number of reviews and analysis, e.g. } \\
\text { (Piller, 2002), and a collection of resources in a Web page } \\
\text { (Piller, 2003). }\end{array}$ \\
\hline
\end{tabular}


From our experience, topics (1) to (4) in Table 1 should require special attention, while topic (5) can be explained in less detail, since it is better introduced in a separate laboratory session in which students interact with a commercial CRM tool. Privacy and legal issues (topic (6)) can be introduced and the concept of trust in the Internet. Mass customization (topic (7)) can be considered optional as an independent topic, but it should at least be mentioned as an area for further study. We have successfully taught the subject in twenty hours, including laboratory sessions to demonstrate the tools to postgraduates. In this time all the issues described in Table 1 were covered to some extent, so that students obtained a global understanding of the topic. Nonetheless, more time to become familiar with the tools and technologies is required if the course is oriented towards implementation issues.

\section{Balancing Marketing and Technical Issues}

The conceptual framework and overall objectives described in the previous section can be tailored to fit diverse student backgrounds and even multi-disciplinary audiences. In this section, we report a number of concrete lessons learned and pitfalls that we have found in teaching ecommerce personalization in corporate training contexts and also in postgraduate studies. In any case, a comprehensive account of the topic of personalization should emphasize the role of measurable business goals and business requirements analysis. Ricci (2004) provides a clear overview of the topic, illustrated by a concrete case study.

\section{Technical and Research-oriented Content}

Rule-based personalization systems as provided in commercial packages provide an easy to learn paradigm for all types of students, irrespective of their background. This is due to the fact that they provide easy to use graphical user interfaces (GUI), which require no previous computing knowledge. Technical programming and configuration details about rule-based engines can be given to students if they possess the following backgrounds:

- If students are knowledgeable on Web programming, the internal programming interfaces of a personalization suite may be introduced.

- If students have a background on expert systems (or AI in general) more complex and subtle issues of rule-based systems can be introduced. A good account of these issues can be found in the discussion of convergence and termination of adaptation rules provided by $\mathrm{Wu}, \mathrm{De}$ Kort \& De Bra (2001). This is specially indicated for PhD students, since many research questions are still unanswered in the field.

Another important technical topic is the understanding of the intricacies of session management and tracking in current Web servers. If appropriate for the background of the students, it can be taught through guided labs in which students build a minimal database user model and are able to capture basic information, e.g. the number of visits to each page in the site, and use it subsequently to implement simple personalization behaviors like changing the level of detail offered in text descriptions for returning visitors. We have experienced that such an approach can be effectively carried out in about eight hours with technical students, using the Java-enabled Tomcat Web server and using a simple Microsoft Access database as the user model repository accessed through JDBC, the standard database connectivity interface used in the Java language.

In addition, the internals of rule systems can be exercised by students with a basic background on expert systems by using open source software, e.g. the Jess expert system shell (Jess, 2003) combined with the Tomcat Web server. It is easy to develop simple categorization examples (e.g. "if the user has visited that page of category $\mathrm{X}$ more than ten times this month and has bought products of that category, then he is a loyal user") to illustrate the role of inference in rule systems. 


\section{Business and Marketing Content}

The concept of relationship value is essential as a global criterion driving the rest of the concepts. As such, our experience indicates that technological issues are better put into context by students after an introduction to relationship marketing as a marketing philosophy. Such introduction should explain a number of common beliefs including the importance of loyalty and customer retention, and the use of relationship value as a generalization of purely financial customer analysis concepts. From a constructivist viewpoint, relationship marketing provides the new conceptual structure required to subsequently build the rest of the knowledge in an integrated, meaningful and practical way (Brown, Collins \& Duguid, 1989). Consequently, the foundations of relationship marketing should be presented first, providing a framework for the rest of the topics.

Engineering-oriented views of marketing fit better the view of personalization as an automated (or semi-automated) relationship management approach than more conceptual views, according to the terminology in (Lilien \& Rangaswamy, 2002). Consequently, statistical software and sample data sets prepared for research provide an interesting complement to personalization topics, since they connect the concept of user modeling with classical market segmentation practices in a seamless way.

For non-technical students, the topic of user modeling can be approached with spreadsheet metaphors, so that the user model can be considered as a large table in which the information about each customer is stored and refined by calculations. Rules and the rationale of collaborative filtering (i.e. recommending items to a given user by exploring the purchase history of other similar users) can be easily understood as a preference modeling procedure. Session tracking can be made optional and the results of adaptive hypermedia technologies do not require a technical AI or database background to be appreciated. Therefore, a streamlined variant of topics in topics (2) to (4) in Table 1 can be provided for non-technical students without losing the capacity of being able to assess the possibilities, limitations and costs of existing personalization techniques.

\section{Conclusions}

Personalization technologies can be considered an important implementation tool for Internet centered marketing strategies, especially in relationship marketing approaches. But teaching personalization technology requires carefully selected and sequenced topics, encompassing both managerial and purely technical issues, which should also be tailored to the given audience. We have described a broad conceptual framework for teaching e-commerce personalization, along with a collection of learning objectives and concepts that provide a comprehensive view of the current uses and capabilities of personalization technologies as applied to a marketing strategy, along with some concrete lessons learned from our experiences in teaching the topic. The described conceptual structure has resulted from experiences in teaching personalization both in postgraduate and corporate training settings, and provides a holistic view that can subsequently be tailored to specific audiences or learning goals.

\section{References}

ATG Dynamo. (2003). ATG Dynamo Web Page. Retrieved September 15, 2003, from http://www.atg.com/

Baylor University. (2003). Hankamer School of Business: MBA Program. Retrieved September 15, 2003 from http://www.baylor.edu/business/splash.php

Bayne, K. (2000). The internet marketing plan: The complete guide to instant web presence. New York: John Wiley \& Sons.

BEA WebLogic. (2003). BEA WebLogic Web Pages. Retrieved September 15, 2003, from http://www.bea.com 
Benyon, D. (1993). Adaptive systems: A solution to usability problems. User Modeling and User-Adapted Interaction, 3(1), 65-87.

Brown, J. S., Collins, A., \& Duguid, P. (1989). Situated cognition and the culture of learning. Educational Researcher, 18( 1), 32-42.

Brusilovsky, P. (2001). Adaptive hypermedia. User Modeling and User Adapted Interaction, 11 (1/2), 87110.

Carnegie Mellon Institute for e-commerce (2003). Master of Science in E-commerce. Retrieved September 15, 2003, from http://web.gsia.cmu.edu/

Chang, K., Jackson, J. \& Grover, V. (2003). E-commerce and corporate strategy: An executive perspective. Information \& Management, 40, 663-675.

Computer Science and Engineering Department of the University of Buffalo (2003). Personalization and Customization in E-Commerce. Retrieved September 15, 2003 from http://www.cs.buffalo.edu/ sbraynov/seninar2003/seminar2003.htm.

Davis, R., Shrobe, H. \& Szolovits, P. (1993) What is a knowledge representation? AI Magazine, 14(1), 1733.

Dhamija, R., Heller, R. \& Hoffman, L. J. (1999). Teaching e-commerce to a multidisciplinary class. Communications of the ACM, 42(9), 50-55.

Dyché, J. (2001) The CRM handbook: A business guide to customer relationship management. Massachusetts: Addison Wesley.

Fensel, D. (2001). Ontologies: Silver bullet for knowledge management and electronic commerce. Berlin: Springer-Verlag.

Fink, J. \& Kobsa, A. (2000). A review and analysis of commercial user modeling servers for personalization on the World Wide Web. User Modeling and User-Adapted Interaction, 10(3-4), 209-249.

Fosnot, C. T. (Ed.) (1996). Constructivism: Theory, perspectives, and practice. New York: Teachers College Press.

Hogan, J. E. (2001). Expected relationship value: A construct, a methodology for measurement, and a modeling technique. Industrial Marketing Management, 30(4), 339-351.

Industrial Marketing and Purchasing Group Web Site (2003) Retrieved September 15, 2003, from http://www.impgroup.org/

Jess (2003). Jess ${ }^{\mathrm{TM}}$, the rule engine for the Java ${ }^{\mathrm{TM}}$ platform. Retrieved September 15, 2003, from http://herzberg.ca.sandia.gov/jess/

Kim, J. K., Cho, Y. H., Kim, W. J., Kim, J. R. \& Suh, J. H. (2002). A personalized recommendation procedure for Internet shopping support. Electronic Commerce Research and Applications, 1(3-4), 301-313.

Kosala, R. \& Blockeel, H. (2000). Web mining research: A survey. SIGKDD Explorations - Newsletter of the ACM Special Interest Group on Knowledge Discovery and Data Mining, 2(1), 1-15.

Lilien, G. L. \& Rangaswamy, A. (2002). Marketing engineering: Computer-assisted marketing analysis and planning $\left(2^{\text {nd }}\right.$ ed). New Jersey: Prentice Hall

Net.Perceptions (2003). Net.Perceptions Web Page. Retrieved September 15, 2003, from http://www.netperceptions.com/

Osterwalder, A. \& Pigneur, Y. (2002). An e-business model ontology for modeling e-business. In Proceedings of the $15^{\text {th }}$ Bled Electronic Commerce Conference, Bled, Slovenia.

Peppers, D. \& Rogers, M. (1997) Enterprise one to one: Tools for competing in the interactive age. New York: Currency Doubleday.

Personalization Consortium (2003). Personalization Consortium Web Pages. Retrieved September 15, 2003, from http://www.personalization.org/

Petrof, J. V. (1998). Relationship marketing — the emperor in used clothes, Business Horizons, 41(2), 7982 .

Piller, F. (2002). Mass customization. In Z. Li \& F. Possel-Doelken, Strategic production networks (pp. 389-421). Berlin: Springer. 
Teaching e-Commerce Personalization Technology

Piller, F. (2003). TUM Research Center mass customization \& customer integration. Retrieved September 15, 2003, from http://www.mass-customization.de

Piller, F., Reichwald, R. \& Möslein, K. (2000). Information as a critical success factor for mass customization. Proceedings of the ASAC-IFSAM 2000 Conference, Montreal, Canada.

Porter, M. (1980) Competitive strategy. New York: Free Press.

Quiroga, L. (2003). Personalization in information delivery. Retrieved September 15, 2003, from http://hypatia.slis.hawaii.edu/ lquiroga/Teaching/pidFA00/ics691syllabus.html

Resnick, P., Iacovou, N., Sushak, M., Bergstrom, P. \& Riedl, J. (1994). GroupLens: An open architecture for collaborative filtering of netnews. Proceedings of the 1994 Computer Supported Collaborative Work Conference, 175-186.

Ricci, R. (2004). Personalization is not technology: Using Web Personalization To Promote Your Business goal. Boxes and Arrows, January, 12 2004, Retrieved December 15, 2004, from http://www.boxesandarrows.com/archives/

Ryals, L. (2002). Are your customers worth more than money? Journal of Retailing and Consumer Services, 9, 241-251.

Rygielski, C., Wang. J. C. \& Yen, D. C. (2002). Data mining techniques for customer relationship management. Technology in Society, 24(4), 483-502.

Sarwar, B. M., Karypis, G., Konstan, J. A. \& Riedl, J. (2000). Analysis of recommender algorithms for ecommerce. Proceedings of the ACM E-Commerce 2000 Conference, 158-167.

Sheth, J. N., Mittal, B. \& Newman, B. I. (1998). Customer behavior: Consumer behavior and beyond. International Thompson Publishing.

Sheth, J. N. \& Parvatiyar, A. (2000). Handbook of relationship marketing. London: Sage Publications.

Sicilia, M. A. \& García, E. (2003). On fuzziness in relationship value segmentation: Applications to personalized e-commerce. ACM SIGECOM Newsletter, 4(2), 1-10.

Smyth, B. \& Cotter, P.(2002). Personalized adaptive navigation for mobile portals. Proceedings of the 15th European Conference on Artificial Intelligence Prestigious Applications of Intelligent Systems.

Smith, P. \& Stobartg, S. (2002). Trends in ecommerce education in the UK. Proceedings of the International Conference on Advances in Infrastructure for Electronic Business, Education, Science, Medicine, and Mobile Technologies on The Internet.

Tinsley, D. B. (2002). Relationship marketing's strategic array. Business Horizons, 45(1), 70-77.

Wedel, M., \& Kamakura, W. A. (1999). Market segmentation: Conceptual and methodological foundations $\left(2^{\text {nd }}\right.$ ed.). Kluwer Academic Publishers.

Wu, H., De Kort, E. \& De Bra, P. (2001). Design issues for general-purpose adaptive hypermedia systems. Proceedings of the 12th ACM Conference on Hypertext and Hypermedia, 141-150.

Yen, B. P. \& Kong, R. C. (2002). Personalization of information access for electronic catalogs on the web. Electronic Commerce Research and Applications 1(1), 20-40.

\section{Biography}

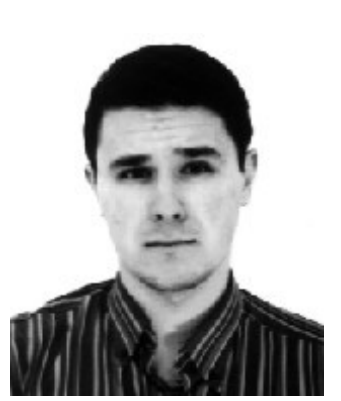

Miguel-Ángel Sicilia obtained a Ms.C. degree in Computer Science from the Pontifical University of Salamanca, Madrid (Spain) in 1996 and a $\mathrm{Ph} . \mathrm{D}$. degree from the Carlos III University in 2003. He worked as a software architect in e-commerce consulting firms, being part of the development team of a Web personalization framework at Intelligent Software Components (iSOCO). From 2002 to 2003 he worked as a full-time lecturer at the Carlos III University, after which he joined the University of Alcalá. His research interests are primarily in the areas of adaptive hypermedia and Web personalization, learning technology, and human-computer interaction. He also teaches personalization and e-commerce subjects at the postgraduate program on e-commerce technology at the University of Salamanca. 